\title{
Allocating the Book Budget: A Model
}

\begin{abstract}
Inflation is currently affecting library book budgets, particularly with respect to the acquisition of serials. A model is proposed which would balance the purchase of serials against the purchase of monographs by individual funding units within the academic library. Special consideration is given to inflation as a cost factor affected by both the form of publication and the subject matter. Applying the model to a specific example demonstrates its use in providing control over collection development and allowing for equitable distribution of book funds among funding units.
\end{abstract}

\section{INTRODUCTION}

C particularly in light of the current inflation and proliferation of new serial titles. If the current trends continue, within a few years the total book budget of many academic libraries faced with constant or decreasing book budgets will be exhausted by serial subscription costs. However, as the serial budget is only one aspect of the total acquisitions problem, no recommendations regarding serials can be made without considering the total acquisition policy/ book budget of the library.

Because of the apparent lack of workable models in the literature, the author formulated basic goals and assumptions for setting budgetary policies. It is imperative to note, however, that the proposed model incorporates decisions that are in fact now being made either explicitly or implicitly by

Mr. Kohut is science librarian at Portland State University, Portland, Oregon. The author gratefully acknowledges the assistance and criticism of his colleagues in the preparation of this article. all academic libraries with limited book budgets. Its major contribution is to clarify the context in which these decisions are being made and to define the underlying principles which should guide these decisions. Because the proposed model is fundamentally expressed as proportions of library-resource units it is applicable regardless of annual fluctuations of the total book budget.

Balancing Sertal

WITH MONOGRAPH ACQUISITIONS

\section{A Model}

Implicit in the concern about serial costs is the assumption that too much of the book budget is devoted to serials. Most libraries could balance the acquisition of monographs with serials so as to maximize their potential to serve the university's information needs. Although such balancing is customarily expressed in terms of dollars, the value of the library to the community of users is defined by numbers of library-resource units. ${ }^{1}$ To the user, therefore, it is the proportion of actual monographs to serials that is critical. To discuss collection development balancing in terms of monies allocated is misleading be- 
cause of differential rates of inflation for each form of publication (e.g., serials vs. monographs) and for each discipline (e.g., biology vs. geography).

Assuming there is an optimum balance between the number of monographs and number of serials that should be received within a given year, this ratio could be best expressed in library-resource units rather than money allocations. In addition, because every discipline has its own optimal balance between serials and monographs, the optimum ratio for the entire library becomes a composite of the ratios for all the disciplines the library supports. These disciplines may constitute funding units; in turn, the general framework of funding units should for the most part reflect the academic structure of the university. ${ }^{2}$

Each funding unit should be assigned a proportion of the total number of library-resource units to be acquired. These proportions can be adjusted to reflect significant changes in academic programs, which are affected by the number of disciplines studied, the level of programs (graduate, undergraduate), and other factors. At any given time, then, there is a multitude of internal constraints which control the collection development for each academic program. Each library must, therefore, apportion library-resource units according to its own objectives.

Although criteria are not set here for identifying an optimum proportional distribution of library resources among funding units, certain factors external to particular institutional situations can be considered. For example, the annual output of all subject literatures varies from subject to subject and statistics can be applied to adjust support for each funding unit according to the size of its respective literature. However, in applying a correction for literature size it must be assumed that each library resource in one funding unit equals that in another in terms of its information value (e.g., a mathematics serial or monograph is as potentially useful to a mathematician as a psychology serial or monograph is to a psychologist), an assumption which may not be necessarily valid. Publication quality control in one field may differ from that in another subject.

Given these variations, the following model involves two fundamental considerations: (1) the proportion of library-resource units to be allocated to each funding unit, and (2) the monograph-serial balance within each funding unit.

1. Let a book budget (GT $=100$ percent) be apportioned among a given number of funding units (N) so that $\mathrm{A}+\mathrm{B}+\mathrm{C} \ldots+\mathrm{N}=\mathrm{GT}$.

2. Let each funding unit (A, B, C, $\ldots, N$ ) be subdivided into a certain percentage of monographs (m) and a complementary percentage of serials ( $\mathrm{s}$ ).

3. The matrix shown in Example 1

\begin{tabular}{|c|c|c|c|c|}
\hline A & B & . . & $\mathrm{N}$ & GT \\
\hline $\mathrm{A}_{\mathrm{m}}$ & $\mathrm{B}_{\mathrm{m}}$ & . . & $\mathrm{N}_{\mathrm{m}}$ & $\mathrm{T}_{\mathrm{m}}$ \\
\hline$A_{s}$ & $\mathrm{~B}_{\mathrm{s}}$ &. & $\mathrm{N}_{\mathrm{s}}$ & $\mathrm{T}_{\mathrm{s}}$ \\
\hline
\end{tabular}

Example 1

results from (1) and (2), where $A_{m}+A_{s}=A, B_{m}+B_{s}=B, \ldots, N_{m}+$ $\mathrm{N}_{\mathrm{s}}=\mathrm{N} ; \mathrm{T}_{\mathrm{m}}$ equals the total percentage of the budget spent for monographs; and $T_{s}$ equals the total percentage of the budget spent for serials.

The proportional allocation of library-resource units among funding units is made prior to, and independently of, any consideration of the desired monograph-serial ratio for each fund. Each fund must subsequently be divided between monographs and serials, both of which are expressed as percent- 
ages of the total number (100 percent) of library-resource units to be acquired. The monograph-serial balance, however, is taken into consideration when correcting for inflation, but only because the rate of inflation of monographs and serials within a funding unit or among funding units is rarely the same.

\section{Inflation}

If there were no variation in inflation among forms of publication-serial vs. monograph-or among publications of various funding units-history, psychology-then proportions of library-resource units could translate directly into dollars. However, comparative studies show that a constant book budget is unevenly eroded by inflation which varies both with form of publication and from one discipline to another. A collection that was in balance in 1967 , for example, is now greatly out of alignment.

Tables 1-3 demonstrate the degree to which inflation affected costs for periodicals during the period $1967 / 69$ through
1972. Chemistry/Physics (Table 1) and Art (Table 2) were selected as examples because they represent the extremes of inflation. Table 3 shows average periodical costs/inflation. Only periodicals published in the United States are represented by these figures.

Comparison of Tables 1-3 indicates that:

1. Chemistry/Physics subscription costs have risen at a more rapid rate than the average, whereas the Art subscription costs have risen at a slower rate. The differences in rates (price indexes) are substantial.

2. Given a constant periodicals budget, by 1972 Chemistry/Physics could continue only 54 percent of its 1967/69 periodical subscriptions; that is, out of every 100 periodical subscriptions in $1967 / 69,46$ would have had to have been cancelled by 1972. Art would have been forced into 20 periodical cancellations per 100 ; that is, a reduction in periodical titles of 20 percent. By the end of this relatively brief interval

TABLES $1-3$

Inflationary Effects on Acquisition of Selected Periodicals

TABLE 1

Chemistry/Physics

\begin{tabular}{lccc}
\hline \hline Year & $(1)$ & $(2)$ & $(3)$ \\
\hline $1967-1969$ & 100 & - & - \\
\hline 1970 & 137 & .73 & -27 \\
\hline 1971 & 157 & .64 & -36 \\
\hline 1972 & 186 & .54 & -46 \\
\hline
\end{tabular}

TABLE 2

\begin{tabular}{lccc}
\multicolumn{4}{c}{ ART } \\
\hline \hline Year & $(1)$ & $(2)$ & $(3)$ \\
\hline $1967-1969$ & 100 & - & - \\
\hline 1970 & 112 & .90 & -10 \\
\hline 1971 & 122 & .82 & -18 \\
\hline 1972 & 126 & .80 & -20 \\
\hline
\end{tabular}

TABLE 3

Averace

\begin{tabular}{llll}
\hline \hline Year & $(1)$ & $(2)$ & $(3)$ \\
\hline $1967-1969$ & 100 & - & - \\
\hline 1970 & 120 & .83 & -17 \\
\hline 1971 & 135 & .74 & -26 \\
\hline 1972 & 153 & .65 & -35 \\
\hline
\end{tabular}

(1) Price index (base year $=1967$ ).

(2) Percentage of periodicals that can be purchased in terms of 1967 dollars.

(3) Number of periodicals per 100 lost to inflation $(1970-72)$.

Data from: "Price Indexes for 1972; U.S. Periodicals and Serial Services," Library Journal 97:2356 (July 1972). 
Chemistry/Physics would have been compelled to cancel more than twice as many periodical subscriptions as would Art.

3. The rate of inflation within each discipline varies from year to year. The price index for Chemistry/ Physics jumped by twenty between 1970 and 1971 and by twenty-nine between 1971 and 1972. Corresponding figures for Art are ten and four. The average rate of inflation was relatively constant (ca. 15 percent annual increase). Between 1970 and 1972, therefore, the rate of increase in periodical costs accelerated for Chemistry/ Physics but decelerated for Art. If these trends continue, the disparity between Chemistry/Physics and Art periodical subscriptions will increase at a more rapid rate than in the past.

Although all funding units were faced with cancellations due to inflation, the original $(1967 / 69)$ balance of the periodicals collection has been grossly distorted. Not only is budgeting according to a proportional distribution of periodicals money misleading, but an across-the-board percentage change in fund money would have only perpetuated this growing imbalance.

Tables 4-7 show the effect of inflation on monographs. Table 5 (Science), 6 (Art), and 7 (Average) were chosen for comparison with the section on periodicals above. Sociology/Economics (Table 4) is added because it displayed the greatest amount of inflation during the study interval. All figures are solely for United States publications; base year is 1967. In contrast to periodicals, monograph costs are not cumulative. However, losses due to inflation can be calculated for each year and summed over the selected interval to obtain a total loss figure for each fund. A constant

TABLES $4-7$

INFLATIONARY EFFECTS ON ACQUiSTTION OF SELECTED MONOGRAPHS

TABLE 4

SOCIOLOGY/ECONOMICS

\begin{tabular}{lccc}
\hline \hline Year & $(1)$ & $(2)$ & $(3)$ \\
\hline 1967 & 100 & - & - \\
\hline 1970 & 153 & .65 & -35 \\
\hline 1971 & 216 & .46 & -54 \\
\hline 1972 & 209 & .48 & -52 \\
\hline Total & - & - & -141 \\
\hline
\end{tabular}

TABLE 6

ART

\begin{tabular}{lccc}
\hline \hline Year & (1) & (2) & (3) \\
\hline 1967 & 100 & - & - \\
\hline 1970 & 130 & .77 & -23 \\
\hline 1971 & 132 & .76 & -24 \\
\hline 1972 & 120 & .83 & -17 \\
\hline Total & - & - & -64 \\
\hline
\end{tabular}

TABLE 5

SCIENCE

\begin{tabular}{lccc}
\hline \hline Year & $(1)$ & $(2)$ & $(3)$ \\
\hline 1967 & 100 & - & - \\
\hline 1970 & 115 & .87 & -13 \\
\hline 1971 & 123 & .81 & -19 \\
\hline 1972 & 124 & .81 & -19 \\
\hline Total & - & - & -51 \\
\hline
\end{tabular}

TABLE 7

\begin{tabular}{lccc}
\multicolumn{4}{c}{ Average } \\
\hline \hline Year & $(1)$ & (2) & $(3)$ \\
\hline 1967 & 100 & - & - \\
\hline 1970 & 138 & .72 & -28 \\
\hline 1971 & 157 & .64 & -36 \\
\hline 1972 & 154 & .65 & -35 \\
\hline Total & - & - & -99 \\
\hline
\end{tabular}

(1) Price index (base year $=1967$ ).

(2) Percentage of periodicals that can be purchased in terms of 1967 dollars.

(3) Number of monographs per 100 lost to inflation $(1970-72)$.
Data from: "1972 U.S. Book Industry Statistics: Titles, Prices, Sales Trends," Publishers' Weekly 203:49 (5

Feb. 1973). Table A-Index of Prices (Per Volume) of Hardcover Books, By Category, 1967 and $1970-72$. 
monograph budget is assumed in the interpretation made below.

1. Inflation as measured by the price index is variable. The general trend is upward, but actually showed a slight decline in most disciplines between 1971 and 1972 . Only Science showed an increase in cost from 1971 to 1972 , but it was not significant. The average monograph cost somewhat less in 1972 than in 1971.

2. Although all disciplines suffered, the effect of inflation differed dramatically between fields since 1967 . Sociology/Economics could purchase slightly less than half the number of monographs as in the base year, whereas Science and Art could purchase about 80 percent.

3. In terms of monographs lost (unpurchased) due to inflation, Science fared best (ca. 50 percent fewer losses than average); Art, next (ca. 35 percent fewer losses than average); and Sociology/Economics, much worse (ca. 40 percent more losses than average).

Inflation has taken a toll which varies both with form of publication and from one discipline to another. Given constant monograph or periodical budgets for each funding unit, a collection that was in balance in 1967 is now greatly out of alignment. Proportional distribution of library-resource units must be translated into a proportional distribution of the book budget by annually taking into account current inflation figures.

In practice monograph inflation adjustments would lag a year behind those for serials. Because serials acquire cumulative costs, serials budgets must be adjusted for inflation and projected for the coming year. The degree of accuracy in the serials budget estimate depends, of course, on the ability to anticipate the rate of serial inflation for each funding unit. This rate must be estimated.

For monographs no inflationary projections are ordinarily made. Though generally upward, the rate of inflation of monographs is variable from year to year, even decreasing for some disciplines in some years. A projected estimate would, therefore, be tenuous at best. In fact, it is unnecessary. To derive an inflation correction for monographs there is no reason why data for the current year could not be compared with data for the past year.

The following example introduces a method for taking inflation into account when balancing serial with monograph acquisition by funding units. The example is purposely kept simple for reason of illustration.

1. Let the total number of libraryresource units to be acquired be divided equally between two funding units (A, B). Fund A consists of 25 percent monographs/75 percent serials; and fund B, 75 percent monographs/25 percent serials, thus:

$\begin{array}{lll} & \text { A } & \text { B } \\ \text { M } & 25 & 75 \\ \text { S } & 75 & 25\end{array}$

Because each fund is 50 percent of the total, the total balance is shown as:

$\begin{array}{lcrr} & \text { A } & \text { B } & \\ \text { M } & 12.5 & 37.5 & 50 \\ \text { S } & 37.5 & 12.5 & 50 \\ & 50.0 & 50.0 & 100\end{array}$

2. Let the following rates of inflation apply: fund A-serials $=20$ percent, monographs $=20$ percent; fund $\mathrm{B}-$ serials $=10$ percent, monographs $=10$ percent, thus:

$\begin{array}{lll} & \text { A } & \text { B } \\ \text { M } & 20 & 10 \\ \text { S } & 20 & 10\end{array}$

Multiplying these inflation percent- 
ages by the figures for total balance (1) yields:

$\begin{array}{lrrr} & \text { A } & \text { B } & \\ \text { M } & 2.5 & 3.75 & 6.25 \\ \text { S } & 7.5 & 1.25 & 8.75 \\ & 10.0 & 5.00 & 15.00\end{array}$

Note that for every 100 library-resource units fund A loses 10 and fund B loses 5 for a total of 15 library-resource units lost to inflation. Fund A will lose 100 percent more library-resource units than fund $\mathrm{B}$, thereby upsetting the 50 50 desired balance unless inflation corrections are made.

3. Multiplying the total inflation loss (15 percent) by the percentages given in (1) yields the following:

$\begin{array}{cccc} & \text { A } & \text { B } & \\ \text { M } & 1.9 & 5.6 & 7.5 \\ \text { S } & 5.6 & 1.9 & 7.5 \\ & 7.5 & 7.5 & 15\end{array}$

Instead of a 10 and 5 loss as in (2) above, each funding unit should lose 7.5 library-resource units. Fund A, therefore, will lose 2.5 library-resource units less; and fund B, 2.5 library-resource units more, if no inflation correction were applied.

4. Subtracting corresponding figures in (3) from those in (2) yields:

$\begin{array}{lrrr} & \mathrm{A} & \mathrm{B} & \\ \mathrm{M} & .6 & -1.9 & -1.3 \\ \mathrm{~S} & 1.9 & -.6 & +1.3 \\ & 2.5 & -2.5 & 0\end{array}$

5. By addition, applying the corrections in (4) to the first total balance (1) produces the following corrected model:

$\begin{array}{lccr} & \text { A } & \text { B } & \\ \text { M } & 13.1 & 35.6 & 48.7 \\ \text { S } & 39.4 & 11.9 & 51.3 \\ & 52.5 & 47.5 & 100.0\end{array}$

By allocating the book budget according to these figures the desired balance of library-resource units
(1) will be maintained. Both funds will receive 7.5 library-resource units less, thereby retaining the initial 50-50 distribution. Note that 52.5 percent of the total budget would be spent by fund A as opposed to a 47.5 percent allocation for fund B. Slightly more would be spent for periodicals than monographs in this particular case.

\section{Application}

All decisions that determine the proportions in the proposed model are, in fact, currently being made in academic libraries. For the most part they are implicit and uncontrolled. However, all the data are generally available and may be compiled in such a format as to be used in the model.

To demonstrate how the balancing model could be applied to a university library, ten funding units, each servicing a particular discipline-oriented collection of the Portland State University Library, were investigated. This examination showed that the model to control collection development can be realistically applied to an academic library and that disparities exist between actual collection development in terms of library-resource units and apparent collection development based on dollar allocations.

Data were compiled for monographs on the basis of orders placed mainly during the first half of fiscal year 197273. As sufficient monographs had already been ordered, a significantly large sample was available to calculate an average price per item (Table 8). Also listed in Table 8 are Bowker's 1972 prices cited in Publishers' Weekly. A comparison of the Bowker figures with those generated internally reveals substantial discrepancies. Only for two fields-Physics and Psychology-are the figures comparable. Only in one field-Art-have books on the average cost substantially more than the Bowker average. In all other disci- 
plines average costs of books purchased by Portland State have been substantially less expensive than indicated by Bowker. Sociology and Economics book costs have been roughly half of the average cost cited by Bowker. For whatever reasons these discrepancies arise, it appears that the Bowker average is inapplicable to this particular book budget. It is concluded, therefore, that inflation corrections can be best determined from internal data; that is, by comparison of average cost increases or decreases for each funding unit from one year to another.

Utilizing internal costs to set inflation corrections introduces a weighted variable into the budget allocation process. This factor may work to the detriment of desired collection development, but if properly controlled is potentially beneficial. If, for example, a number of very expensive items were purchased out of a particular fund, this would boost the fund inflation correction. In the following year-assuming a constant budget-this fund would benefit at the expense of other funding units in terms of actual dollars available to spend. Ostensibly, the fund would be rewarded for making expensive purchases; yet in reality this fund's proportion of the total book budget in the model would be unchanged, and the fact that each serial subscription would become a permanent commitment by its fund should encourage discrimination in ordering. Without this weighted variable an inordinately expensive serial would seriously limit the total number of library-resource units that fund could acquire, thereby stunting development of the collection it supports.

This example balances the importance of a very expensive commitment to a particular community of patrons against total library needs. With a limited budget such considerations must be made whether the model is adopted or not. The model merely provides a mechanism for distributing the costs of such burdens.

From the data in Table 8 an estimated number of monographs ordered/to be ordered in fiscal year 1972-73 was calculated for each funding unit. These values along with the number of annual/irregular serials and periodical subscriptions for each funding unit were used to construct Table 9. All figures are percentages of total library-resource units acquired by the ten funding units analyzed. It is a working standard based on fiscal year 1972-73. The growth rate of the collection in 1972/73 was highly variable from one form of publication to another and especially

\section{TABLE 8}

Comparison of Portland State Universtry Library Average Cost/Monograph (1972/73 Fiscal Year) with Bowker's Frgures (1972 Calendar Year)

\begin{tabular}{lccccc}
\hline \hline Fund & Sample Size & $\begin{array}{c}\text { Allocation } \\
\text { (Monograph) }\end{array}$ & $\begin{array}{c}\text { Average Cost } \\
\text { (PSU) }\end{array}$ & $\begin{array}{c}\text { Average Cost } \\
\text { (Bowker) }\end{array}$ & Difference \\
\hline Applied Science & 234 & $\$ 2,763.56$ & $\$ 11.85$ & $\$ 16.11$ & $-\$ 4.26$ \\
Art & 241 & $4,353.79$ & 18.07 & 14.94 & +3.13 \\
Business Administration & 397 & $3,025.24$ & 7.62 & 12.45 & -4.83 \\
Economics & 339 & $3,221.12$ & 9.50 & 16.93 & -7.43 \\
Education & 578 & $3,306.97$ & 5.72 & 10.26 & -4.54 \\
English & 762 & $6,950.17$ & 9.12 & 12.03 & -2.91 \\
History & 723 & $8,481.22$ & 11.73 & 14.92 & -3.19 \\
Physics & 219 & $3,554.81$ & 16.23 & 16.05 & +0.18 \\
Psychology & 301 & $3,076.78$ & 10.22 & 10.44 & -0.22 \\
Sociology & 422 & $3,616.11$ & 8.57 & 16.93 & -8.36 \\
\hline
\end{tabular}

- Data from: "1972 U.S. Book Industry Statistics: Title, Prices, Sales Trends," Publishers' Weekly 203:49 (5 Feb. 1973). Table A-Index of Prices (Per Volume) of Hardcover Books, By Category, 1967 and 1970-72. 
TABLE 9

Model Based on Ten Funding Units for the Portland State University Library

\begin{tabular}{lcccr}
\hline \hline Fund & Monographs & $\begin{array}{c}\text { Serials } \\
\text { (Annual/Irregular) }\end{array}$ & Periodicals & Total \\
\hline Applied Science & 3.9 & 0.3 & 2.3 & 6.5 \\
Art & 3.6 & 0.3 & 1.1 & 5.0 \\
Business Administration & 6.6 & 2.7 & 5.6 & 14.9 \\
Economics & 5.1 & 1.1 & 2.1 & 8.3 \\
Education & 10.3 & 1.2 & 3.5 & 15.0 \\
English & 10.4 & 1.1 & 3.6 & 15.1 \\
History & 10.6 & 1.4 & 1.8 & 13.8 \\
Physics & 2.9 & 0.9 & 1.6 & 5.4 \\
Psychology & 6.3 & 0.5 & 1.8 & 8.6 \\
Sociology & 6.3 & 0.3 & 1.2 & 7.8 \\
\hline \multicolumn{1}{c}{ TOTAL } & & & 100.4 \\
\hline
\end{tabular}

- Total percentages (100 percent) slightly inaccurate because fund figures rounded to one decimal place.

among funding units. It is obvious that Business Administration, Education, English, and History actually obtained a much greater percentage of library-resource units than Applied Science (Engineering), Art, and Physics. This pattern of collection development was completely unexpected when compared to the relative distribution of money among these funds.

\section{Conclusion}

The proposed model does not, of course, solve budgetary problems. Through appropriate inflation correc- tions, however, it provides a mechanism for equitable distribution of book budget funds. An ancillary benefit is that it clearly maps the general direction in which the collection is developing and allows better control over collection development. Given this model, adjustments necessary to steer the collection toward selected goals could be identified and made despite fluctuation in the total book budget. The model is also flexible in that it can incorporate any number of funding units (e.g., Physics, English) and subdivisions thereof (e.g., periodicals, monographs).

\section{References}

1. One volume as defined by and reported to the U.S. Office of Education in the annual Higher Education General Information Survey, or one reel of microfilm or eight Microcards or microfiche as reported on the same survey. For reporting purposes, a volume is a physical unit of any printed, typewritten, handwritten, mimeographed, or processed work contained in one binding or portfolio, hardbound or paperbound, which has been classified, cataloged, and/or otherwise prepared for use. Include bound periodical vol- umes. Include government documents that have been classified and cataloged, counting as a volume such material as is contained in one binding or portfolio.

2. It is recognized that although funding units will, for the most part, be defined by disciplines, exceptions are necessary. For example, those acquisitions that are necessary but so interdisciplinary as to require a special fund (e.g., General Fund) and those more reasonably grouped by form of publication (e.g., Newspaper Fund). 